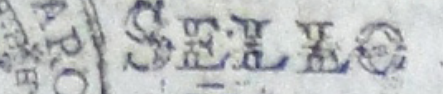

(3)

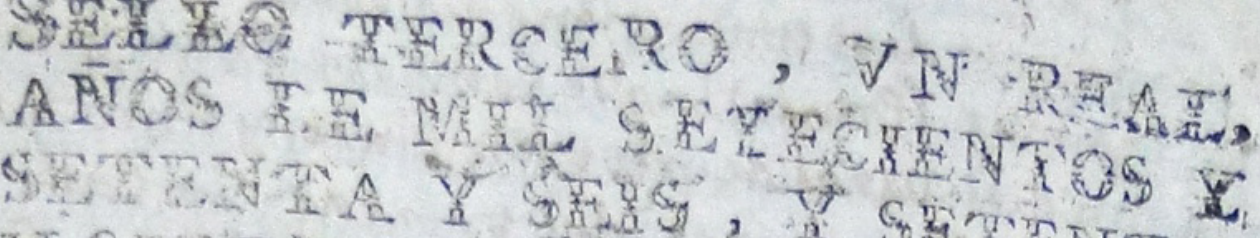

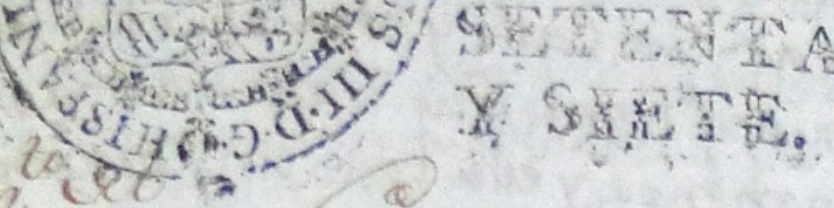

(1) $n$ d nombxe de Ds tod

gra Arnen. Seroun grant." Gita Carlo Imirnexa Voluntao Viexen como yo el tuxal de eitar Cundad dehexino Preibiten

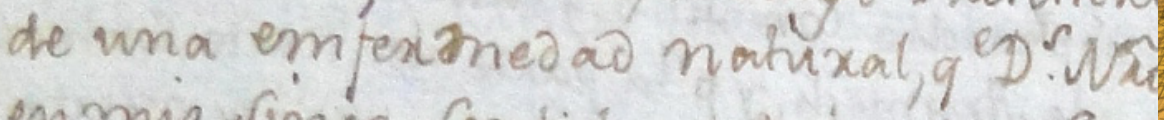
enmir vinco sentidos y potencias an te g'er Cora natuxal atooa Gíatuxa; venkion gi hodo Gxutiano deve tenex, Exeiendo conno fixm te Geo enel mu midact, $\rho^{\text {e }}$ xtifo y espixim sto hes, pexior aradeno, y entodo lo dem as g'tiene, y Grees Yolec. Co mitu $v^{20}$ SECCIÓN DE BUENA FUENTE inx com $[\mathrm{dbf}]$

$x^{\gamma}$ mi at

Sima a nombie

Con Cni

nesia on

[Isabel Castro Olañeta y Leticia Carmignani]

deha nao

Un informe de 1607 sobre el Valle de Catamarca y la Sierra de Santiago del Estero

coo dern ta Couz. Ctoxino deg fuce prohistoria

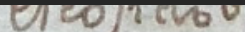

de Gita, on

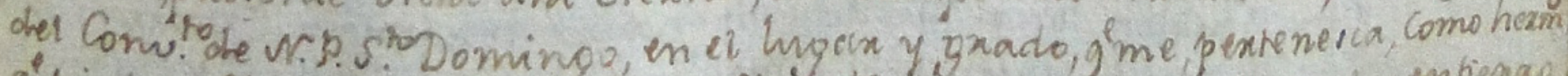
y demar 


\title{
Un informe de 1607 sobre el Valle de Catamarca y la Sierra de Santiago del Estero
}

\section{A 1607 Report on the Catamarca Valley and the Mountains of Santiago del Estero}

\author{
ISABEL CASTRO OLAÑETA \\ LETICIA CARMIGNANI
}

\begin{abstract}
Resumen
Ofrecemos una carta del Teniente de Naturales Juan de Betanzos al Gobernador del Tucumán Alonso de Ribera, fechada en Alvigasta el 7 de febrero de 1607. Contiene el informe de su Visita al "partido de la Sierra", jurisdicción de Santiago de Estero, que incluía las sierras occidentales y el valle de Catamarca. Al momento, es el único Informe de Visita que conocemos en original, realizado por uno de los Tenientes de Naturales nombrados por el Gobernador en el marco de su proyecto de visitar la tierra, aplicar las Ordenanzas de Abreu de 1576 y desagraviar a los naturales.
\end{abstract}

Palabras clave

Partido de la Sierra - Valle de Catamarca Santiago del Estero - Gobernación del Tucumán - Indios

\begin{abstract}
We offer a letter of Teniente de Naturales Juan de Betanzos to the Governor of Tucuman Alonso de Ribera, signed in Alvigasta on 7 February 1607. It contains the report of his Visit to the district of Partido de la Sierra in the jurisdiction of Santiago de Estero, including the western mountains and the Catamarca Valley. At the moment, is the only original Visit Report known, written by one of the Tenientes de Naturales appointed by the Governor as part of his project to visit the Governorate, to apply the Abreu's Ordinances and to relieve the Indians.
\end{abstract}

\section{Key words}

Partido de la Sierra - Catamarca Valley - Santiago del Estero - Governorate of Tucuman - Indians

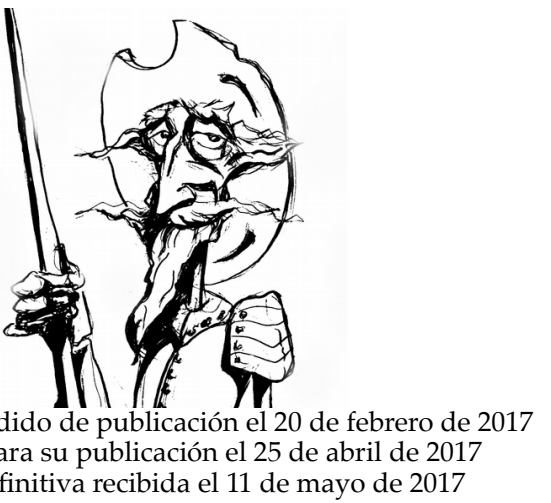

Isabel Castro Olañeta, Universidad Nacional de Córdoba, Argentina; e-mail: isabelcastrox@gmal.com

Leticia Carmignani, Consejo Nacional de Investigaciones Científicas y Técnicas, Universidad Nacional de Córdoba, Argentina; e-mail: leticiacarmignani@gmail.com

Esta obra se publica bajo licencia Creative Commons. Atribución-NoComercial-CompartirIgual Internacional

(cc) BY-NC-SA

Castro Olañeta, Isabel; Carmignani, Leticia "Un informe de 1607 sobre el Valle de Catamarca y la Sierra de Santiago del Estero", Prohistoria, Año XX, núm. 27, jun. 2017, pp. 99-105.

\section{Introducción al Documento}

Con el encabezado "Carta para el Gobernador de Tucumán" presentamos aquí la transcripción paleográfica de un documento inédito que, si bien ya había sido referenciado y analizado por otros investigadores, a pesar de su importancia aún no había sido estudiado en profundidad, específicamente y comprendido su 
contexto de producción. ${ }^{1}$ Se trata de una carta al gobernador del Tucumán Alonso de Ribera, fechada el 7 de febrero 1607 y firmada por Francisco de Betanzos en la ciudad de Alvigasta. ${ }^{2}$

El conocimiento del contexto y un análisis del documento nos permitieron deducir que esta carta se correspondía con el Informe original de un Teniente de Naturales designado por el gobernador Ribera, y versaba sobre su visita realizada al Partido de la Sierra y Valle de Catamarca, jurisdicción de la ciudad de Santiago del Estero. El Informe describe el recorrido y accionar del Teniente por el Valle de Catamarca y la ladera oriental de las sierras de Ancasti y Alto-Gracián, ofreciendo información sobre la geografía y la situación de las sociedades indígenas y las encomiendas de la región. ${ }^{3}$

Dicho documento fue escrito en soporte papel, con un tipo de letra o que tiende al tipo denominado como escritura procesal (pero no encadenada) y se caracteriza por la ligazón irregular de palabras y letras, producto de la rapidez de la escritura, y por no regirse por preceptos caligráficos ni reglas ortográficas fijas. ${ }^{4}$ Se encuentra en un excelente estado de conservación, sin presentar manchas, roturas, quemaduras ni deterioro de tipo alguno. Ocupa cuatro folios rectos y vueltos y presenta una foliación desde el 1 al 4 que hemos respetado, a pesar de haber sido agregada posteriormente.

Nuestro trabajo consistió en la trascripción paleográfica de la Carta, la cual fue ajustada a las "Normas para la Transcripción de Documentos Históricos

\footnotetext{
${ }^{1}$ El documento fue localizado por Josefina Piana y presentado por ella en su libro, al identificarlo como el Informe del teniente del valle de Catamarca, Francisco de Betanzos. (PIANA, Josefina Los indígenas de Córdoba bajo el régimen colonial 1570-1620, Córdoba, 1992, p. 252). También fue utilizado por Lorandi, (LORANDI, Ana María "El mestizaje interétnico en el noroeste argentino", en TAMOEDA, Hiroyasu y MILLONES, Luis (eds.) 500 años de mestizaje en los Andes. Senri Ethnological Studies, 33, pp. 162-163) y específicamente, Schaposchnik lo analizó en un estudio sobre la delimitación del valle de Catamarca (SCHAPOSCHNIK, Ana "Cuando Catamarca aún no era Catamarca. Etnohistoria de Colpes (siglos XVI y XVII)", Población y Sociedad, 4, 1996, p. 142).

${ }^{2}$ En el margen superior derecho del folio 1 recto se agregó, posteriormente y con una grafía diferente a la de la carta, la escritura " 200 . Salta, $7 / 2 / 1607$ ". Esta referencia que no pertenece al documento original, es errónea y causada por una lectura equivocada del lugar donde fue firmado el documento (Salta por Alivigasta). Este error ocultó un dato de la mayor relevancia, que es que el teniente Betanzos se refiere al Partido de la Sierra de Santiago, como su distrito a visitar el cual incluía el Valle de Catamarca.

${ }^{3}$ Sobre la Visita y el nombramiento de los Tenientes de Naturales, ver: CARMIGNANI, Leticia "Las visitas de los tenientes de naturales a los partidos de pueblos de indios de la gobernación del Tucumán (1606-1607)", Corpus. Archivos virtuales de la alteridad Americana, vol. 3, núm. 2, 2013, Julio/Diciembre 2013 pp. 24-27, http://corpusarchivos.revues.org/548; CARMIGNANI, Leticia "'Soy en esta provincia muy odiado de los vecinos encomenderos'. El gobernador del Tucumán Alonso de Ribera y su proyecto político (1605-1611)", Memoria Americana. Cuadernos de Etnohistoria, vol. 23, núm. 1 (2015), Sección Etnohistoria, Facultad de Filosofía y Letras-UBA, Buenos Aires, enero-junio 2015, pp. 11-38. http://ppct.caicyt.gov.ar/index.php/memoriaamericana/article/view/5862/6183.

CASTRO OLAÑETA, Isabel "La Numeración de los indios del partido del Río Salado. Santiago del Estero, 1607. Encomiendas y servicio personal", Corpus. Archivos virtuales de la alteridad Americana, vol. 3, núm. 2, 2013, Julio/Diciembre 2013 http:/ / corpusarchivos.revues.org/535

Un estudio específico sobre el contexto de producción de este documento y la información que brinda, CASTRO OLAÑETA, Isabel y CARMIGNANI, Leticia "La Sierra de Santiago y el Valle de Catamarca a principios del siglo XVII: reflexionando sobre una nueva regionalización", en este mismo número de la Revista.

${ }^{4}$ TANODI, Branka. La escritura en Córdoba del Tucumán (1573- 1650), Universidad Nacional de Córdoba, Córdoba, 1994.
} 
Panamericanos" aprobada en la Primera Reunión de Interamericana sobre Archivos, 1961 en Washington. ${ }^{5}$ Este tipo de transcripción propone una intervención mínima del documento para facilitar su lectura, pero sin modificar su ortografía (sólo en cuestiones indispensables) y estructura gramatical. Corresponde a una trascripción, casi literal, que interviene sólo para separar palabras que en la grafía del documento se encuentran unidas, restituir las mayúsculas para los nombres propios, homogeneizar el uso de las $\mathrm{U}, \mathrm{V}$ y B y extender las abreviaturas. Además, hemos introducido una separación de párrafos mínima, a los efectos de facilitar el ordenamiento de la información del documento.

Informe sobre la visita al Partido de la Sierra y valle de Catamarca, enviado por el teniente de naturales Francisco de Betanzos al gobernador del Tucumán, Alonso de Ribera. Alivigasta, 7 de febrero de $1607 .{ }^{6}$

[4v.] Carta para el Governador de Tucuman

[1r.] Muy ilustre Governador

Por no averse ofreçido cosa de consideraçion no e hecho esto a menudo hasta agora que dado buelta a mi distrito y e visto lo que ay en que dar quenta a Vuestra Señoria.

Ayer bine del valle de Catamarca a esta sierra donde e visto la ruina que ay ques lastima de ver los yndios desnudos y por poblar que solos dos pueblos ay poblados y lo demas estan apartados del español por aquellos montes donde anreçivido notables agravios que solo asisten los encomenderos a desollarlos y no a reduçirlos y vestirlos ni asistir a que hagan chacaras ni cossa en favor de los pobres naturales porque ni se an guardado ordenanças ni an querido saver que son por no guardallas.

En lo que toca hacienda de comunidad ni en particular, no tienen ni que comer mas que algarroba y con essa sirven y los encomenderos tienen todos algodonales y algunas simenteras con poca raçon porque bien pudieran pues ay riego que tanbien le ubiera para los yndios, por esta causa an ydo en desminuçion con las demas de malos tratamientos y diçen los vezinos que son malos yndios yo digo que son los mejores desta tierra y tal me an pareçido pues sirven con tan malos tratamientos y si algunos ay çimarrones que seran hasta veinte yndios en todo el valle lo son con mucha raçon por lo que yo e visto y dire a Vuestra Señoria.

Haçiendo padron y dandoles a entender lo que Vuestra Señoria manda por [1v.] las ordenanças del gobernador Gonçalo de Avrego y Figueroa y como an de acudir a servir y que mi venida a sido para anparallos en justiçia, fui haçiendo esto y a tres pueblos que ube andado en el valle lo supieron los çimarrones y por la notiçia que de otros dellos tenian de mí desta sierra que se avian benido por

\footnotetext{
${ }^{5}$ TANODI, Branka "Documentos históricos. Normas de Transcripción y Publicación", Cuadernos de Historia. Serie Economía y Sociedad, núm. 3, Centro de Investigaciones de la Facultad de Filosofía y Humanidades, Universidad Nacional de Córdoba, Córdoba, 2000, pp. 259-270.

6 Archivo y Biblioteca Nacionales de Bolivia. Correspondencias, Audiencia de Charcas, 580. Transcripción paleográfica de Isabel Castro Olañeta y Leticia Carmignani. Agradecemos especialmente a Silvia Palomeque su generosidad al poner el documento a nuestra disposición y a Álvaro Torero quien colaboró dedicadamente en el control de esta transcripción.
} 
ver que en su favor avia andado por aqui yo antes que passara al valle, y ansi vinieron seis yndios destos dichos çimarrones de la encomienda del capitan Joan Vautista Muñoz y otros dos de la encomienda de Pedro de Maydana que fueron los que vino a buscar Garcia Barata, y me dijieron que venian a presentarse ante mí para que los oyese de justiçia pues engañavan a los governador esdiçiendo que no querian servir, y dicha su querella de sus amos y pobleros les dije que yo les asegurava las vidas a todos los demas que alla quedavan y que les haria pagar lo que les deviesen y deshazer sus agravios y asegureles con la raçon que tienen, y otro dia de mañana me vinieron a pedir dos caçiques del dicho Joan Vautista y estos indios que querian yr por los demas yo les di todo el favor que pude y les ofreçi el traelles su algarrova que tenian cojida y despache a estos dos caçiques y a un yndio dellos muy amigo de los que avian benido y me prometieron dentro de seis diastraellos. Oy haze quatro y sere presto alla porque ynporta mucho anparar aquellos pobres.

Yo e dejado lo mas que e podido reparado y notificado a sus vezinos los pueblen y hagan chacaras y den lo que an menester para vestir a los desnudos y dalles que coman con lo demas que resan las ordenanças por lo qual quedaron contentos los naturales y con muchas esperanças de que no abra çimarrones.

Hare aqui relaçion a Vuestra Señoria, el sujeto del valle para que Vuestra Señoria bea el orden del y de la manera que piden los que quieren hazer maloca como quando vino Garcia Varata.

Es un valle entre dos sierras las mas altas que ay en la governaçion que casi estan a norte sur y ansi corre el valle, la una es la de Londres que por aquella parte que cay al valle no se [2r.] puede andar ni comunicar con los yndios de Londres si no es con mucha dificultad por el mal camino que ay y desta ay otros tres passos peores que la cordillera, el anchor del valle es de tres leguas y quatro por donde mas hasta lo poblado que alli se enbeve el agua del rio y se aparta la una sierra la vuelta de La Rioja y la otra la buelta de Cordova, y ensanchan alli tierra despoblada y lo poblado el rio abajo desde el primer pueblo seran doçe leguas hasta donde se hunde el agua y todos los pueblos estan sobre el rio solos tres que goçan de unos arroyos que siempre salen de la sierra de Londres y a una parte y otra del rio es todo algarrobales con buenas tierras para el riego y puesto en qualquiera parte pareçen las sierras muy altas como peñas tajadas y a esta caussa no pueden premaneçer çimarrones si los que ban a buscallos fuesen soldados aunque mejor fuera las vezes que se an levantado que ubieran venido juezes a desagraviallos que nunca ubiera yndio que no sirviera porque diçen los yndios una raçon muy buena: si nos bamos al monte porque nos cargan sin darnos a comer de aqui a Tucuman y La Rioja y nos fuerçan nuestras mugeres y visto que ya estamos huidos porque raçon no mataremos al yndio que nos enbian a reconoçer y a sus parientes; que respuesta se les puede dar a esto, particularmente sabiendo questan por agravios en el monte y mas en esta ocassion que ancomençado a venir pero los que bienen a maloca andanse de pueblo en pueblo y sus parientes les avisan y aun en los pueblos haçen agravios notables porque se me quejaron yndios e yndias de que quando vino Garcia Barata como fue la maloca por un yndio que le mataron entro en el pueblo del matador ques de Pedro de Maydana y consintio que flechasen a un hermano del matador y a su muger y apaliaron algunos yndios y tomando yo muestra de los yndios pareçieron pidiendo juztiçia y el matador presente y dijo: aqui estoy que por mi se bino a hazer la maloca y ataque a mi hermano y muger; y lebantaron la 
poca ropa que tenian y enseñaron los flechaços, yo le dije [2v.] al delinquente que por que avia muerto al yndio de Barata, dijo que a él buscavan pero que no save quien lo mato, dijole el ynterpete: ben aca yo no bine con Barata por lengua como agora como diçes que no eres tu; respondio que él estava huido en el monte con otros por malos tratamientos y que no se acordaron de otro mas que del y como en aquel tiempo tenia yo la masa començada para que biniesen los demas no consenti que le tratasen mal y dije que hariajuztcia por el agravio que Barata les hizo y soy obigado a hazerlo. Ay de estas quejas en el valle muchas y ansiquando se biene a maloca no se a de tomar ningun pueblo del valle como se haze en otras partes yo confio en dios que an de venir todos de lo que ubiere desto y lo demas dare quenta a Vuestra Señoria.

De una parte a otra ando ques tan apartado este distrito y tan malos caminos que la cordillera no es peor. La minuta de los yndios del valle hasta los del capitan Jinez de Lillo no allegan [sic] a treçientos y setenta sacados los biejos que por todos sera quatroçientos y en esta sierra ay treçientos con los biejos tassadamente.

Si en particular mandare Vuestra Señoria que de cada pueblo haga a Vuestra Señoria relaçion la hare que por no enfadar no la hago mas larga solo de que en el valle de Catamarca todo el trato es algodon y por mucho que ay andan los yndios desnudos y muchos con plumas de avestruz cubiertas sus berguenças y aun descubiertas muchos y muchachas que me dava mucha pesadumbre; que si yo lo ubiera visto antes y que no estuviera Vuestra Señoria en esta tierra que tan bien acude al reparo de los pobres me moviera la conçençia dejar de dar parte a Su Magestad y Real Audiençia de La Plata y en alguna manera me pessa de ver la poca conçençia que tienen los que tienen yndios tan maltratados y querer remediarlo todo de golpe es proçeder en ynfinito ello se yra entablando aunque les pesse con la juztiçia que Vuestra Señoria mandara guardalles.

En lo que toca mi particular me holgara no aver venido adonde tanta juztiçia es menester y tierra que tan poca consiente y acudir en otra a servir a Su magestad y a Vuestra Señoria como siempre lo e procurado hazer, [3r.] anme pedido los caçiques que pues Vuestra Señoria los anparado en juztiçia les haga merçed para que sean respetados de que en cada pueblo se nombre un alcalde o que se le de nombre que traiga barra [sic] para poder a los yndios ajenos mandarles que no entren a hazer boracheras ni a otras cossas malas en los pueblos y para que manden sus yndios en lo que el poblero les ordenare sin que otra persona lo haga ni tome mano y pareçeme que traen raçon porque les ablamos bien como se guardan las ordenanças y si alguno mereçiere castigo lo prendan con orden del español para que yo vea el castigo que mereçe y no que los castigue otro y por muchas caussas de quebrantamientos y fuerças que pueden suçeder en en el ynter que yo ando de una parte a otra.

Tambien me pidieron algunos que porque avian de traer armas los yndiosdesta sierra y valle que no ay yndio que no tiene arco y flechas y se enborrachan y andan avalentados viendose con armas y pues en el Piru no se permiten sirvasse Vuestra Señoria de que a un tiempo y un dia tengan orden en todos los pueblos de que se quiten con cordura dandoles a entender que estaran guardadas para quando se ofrezca maloca y tanbien se les de a entender que no traiendo ninguno armas no tendran de quien guardarse y ponelles una gran pena al que las trujere. 
En lo que toca a las borracheras o bever es menester poner orden y ansi la queria de Vuestra Señoria porque se las vedan los pobleros y se ban al monte a hazerlo donde çuçeden algunas desgraçias yo creo que en el Piru tienen licençia para vever en los pueblos no lo se de çierto mas se que lo diçen algunos y siendo ansi bien podian hazerlo aca los domingos y fiestas donde los bea el español y quel que trujere bara que no beva como lo hazen en las fiestas en el Piru. Suplico a Vuestra Señoria se sirva de mandarme dar avisso de lo que hare en esto porque conbiene mucho acudir al remedio.

[3v.] En lo que toca a los padrones se hazen y se an hecho como Vuestra Señoria manda por su ystruiçion sin agraviar ninguna de las partes en el reservarlos los biejos y biejas y los que derecho tienen que hasta aqui nada se guardava ni la semana a los yndios y en el valle ningundia que en esta sierra guardavasse algunos biernes y savados para hacer sus chacaras y eso veran en pocas partes, solo un pueblo e hallado en el valle con orden en tener chacaras y en guardalles alguna cossa de las ordenanças ques en el del capitan Luis de Gallegos y dan mucho fructo treinta yndios que alli tiene se cojeran este año dos mill arrobas de algodón. Hasta agora a sido todo cojer algarroba que algunos pueblos no eenpadronado por no estar juntos pero a todos los caçiques y pobleros les e dado la orden que an de tener y sera menester enbiarles a los pobleros ordenanças que nadie las tiene.

En quatro pueblos que ay desde donde se juntan las sierras de Londres y esta con otra sierresita para arriba que aunque es doctrina del valle haze angostura y luego ensancha otro valle arriva hasta el pueblo de Jinez de Lillo, que todo se entitula Catamarca que aunque e dicho a Vuestra Señoria no aver mas de doze leguas se entiende de lo angosto abajo que de alli arriba ay otras catorçe de mala tierra de andar porque se passa un rio veynte y dos vezes para yr a estos quatro pueblos y con las muchas aguas de este año no e podido passar solo e dado a entender lo que an de guardar y agora e de entrar por la parte de Tucuman porque el dicho rio no se puede andar por parte de abajo, en estos pueblos no se coje algodón ay crias de mulas y ganados solo en el del capitan Jinez de Lillo no lo ay acuden a hilar y a otras granjerias, tierra de muchas papas y muy buen maiz y mucho ganado de la tierra.

En esta sierra es el trato lienço y alpargatas, cordovanes, cria de mulas y ganados y en lo que toca las alpargates y guascas dicen los caçiques y indios ques en lo que mastravajan los naturales por el cojer del chaguar [4r.] y la ocassion de ausentarsse los yndios en toda esta governacion es el terrible travajo con que se coje y pudiera Vuestra Señoria remediarlo siendo servido dentro de un año con mandar a los vezinos que siembren cañamo pues les sera mas barato y sacaran mas fruto que de una anega sale mas que pueden buscar çien yndios en un año y lo puede beneficiar uno solo y por poca semilla que se meta en esta governacion abra mucho en poco tiempo porque se da bien y es tierra aparejada para ello cosa es que ynporta esto mucho que como digo a Vuestra Señoria passan los yndios mucho travajo y particularmente como les dan tareas y esto es en toda la governaçion.

Tambien doy quenta a Vuestra Señoria acerca de las doctrinas porque encargo mi conçençia en no hazerlo, muy mal doctrinados estan todos estos yndios y los del valle, la raçon es que nadie quiere quentos con clerigos en reprezendelles suelen se estar en una parte todo el año y yrse a las ciudades y no conocen quando bienen a dar una buelta si son christianos o no lo son pues e 
hallado yndias de sesenta años por christianas y que no se a dicho missa dos bezes en el año en los mas pueblos y parecen mill amançebados y enfermos que se mueren como vestias y aun e tenido quejas que no se pueden dezir de yndias y el dia que an de acudir con alguna ofrenda acuden ellos o sus criados a quitalles las gallinas. E quitado un mal usso que en toda la governacion lo ay y yo no lo e de permitir de que los yndios lleven la caja del ornamento a cuestas, que tope el clerigo del valle que venia de dies leguas que ay de lo de Granero a lo de Luis de Medina con dos yndios que traian la caja a cuestas y le dije que como no se dolia de aquellos desventurados pues teniacavallo en que traella y aunque era la primera vez que le vi y deseava vessar su mano, se lo reñi mucho con otras cossas a solas y me respondio que estava entablado en esta tierra este usso, yo le dije que no se había de usar en mi tiempo ni servirse de ningunyndio para cargallo ni que los fiscales ni sus mujeres [4v.] hilen ni hagan otra cosa mas que sevir en la iglesia y quando este en el pueblo el cura servirse del fiscal y de su muger y en todo lo que mas manda el Sinodo. E visto yglesias que una cruz ni ymajen no ay en ellas y que pareçe que desde la guerra de granada no a entrado jente dentro ni los muchachos no saven los nombres sino todo poco mas a menos seria raçon que anduviesen de los pies pues bienen a las doctrinas con esta obligacion, atrevome a dezir esto en christiandad para que lo sepa Vuestra Señoria a quien guarde nuestro señor y en mayor estado y descansso aumente como puede.

De Alivigasta de febrero 7 de 1607.

Criado de Vuestra Señoria, Francisco de Betanços.

Isabel Castro Olañeta Leticia D. Carmignani Córdoba, Argentina, mayo de 2017 